\title{
Antik Dönemde Seramik Üretim Tekniklerine Dair İzler: Rhodiapolis Örneği
}

\author{
Öğr. Gör. Dr. Erdal Çetintaş
}

Makale Geliş Tarihi: 20.03.2018 Yayına Kabul Tarihi: 01.05.2018

\section{Özet}

Seramik, insanlık tarihi açııından en eski malzemelerinden biri olmasının yanı sıra üretildiği dönemin sosyolojisi kültürü ve teknik gelişimi açııından önemli bilgiler sunmaktadır. Bin yıllar boyunca, dünyanın büyük bölümünde yaygın olarak üretilen seramikler günümüzde son teknolojiye ayak uydursa bile, hala bazı konularda eski çağlara ait görüş, anlayıs ve yöntemler geçerliliğini korumaktadır ve geleceğe ışık tutacak niteliktedir. Bu bağlamda; Anadolu kültür tarihi, özellikle arkeoloji dünyası için önemli bir bölge olan Likya, 19. yüzyıldan günümüze birçok gezgin, tarihçi, arkeolog ve bilim insanının bir bölge olan Likya, 19. yüzyıldan günümüze birçok gezgin, tarihçi, arkeolog ve billim insanının
araştırma yaptığı ve seramiklerin yoğun olarak bulunduğu bir bölge olmuştur. Likya Bölgesi'nin önemli kentlerinden birisi de Rhodiapolis antik kentidir. Bu çallşmada; Rhodiapolis kazılarında bulunan yerel seramik üretim atıklarının üretiminde izlenen şekillendirme ve pişirme yöntemlerine dair uygulama aşamaları incelenmiş ve günümüz üretim yöntemleriyle arasındaki benzerlik ve/veya farklılıklar değerlendirilmiştir.

Anahtar Kelimeler: Seramik, Üretim Tekniği, Rhodiapolis, Şekillendirme, Pişirme

\section{TRACES OF CERAMIC PRODUCTION TECHNIQUES IN ANTIQUITY:} RHODIAPOLIS SAMPLE

\section{Abstract}

Ceramic is one of the oldest materials in terms of human history, as well as the socio-cultural and technical development of the period of time it provides important information. For thousands of years, even if the latest technology is to adapt to today's, Ceramics produced widely in most parts of the earth, still, some of the old age views, understanding and methods remain valid and are capable of shed light on the future. In this connection; Anatolian cultural history, Lycia which is an important place especially for the world of archeology that many researchers and scientists have researched and where ceramic production are founded since the 19th century. The city of Rhodiapolis is one of the most important cities of the Lycia region. In this study; the application stages of shaping and firing techniques followed in the production of local ceramic production wastes in Rhodiapolis excavations have been examined and the similarities and/or differences between today's production methods have been evaluated.

Keywords: Ceramic, Production Techniques, Rhodiapolis, Shaping, Firing 


\section{Giriş}

Toprağın pişirilmesiyle ortaya çıkan seramiğin, insanlık tarihinin en eski kültür kalıntılarından biri olduğu bilinmektedir. İnsanoğlunun her zaman toprakla iç içe yaşamasından dolayı, ana malzemesi kil olan seramiğin bulunması ve kullanılması kaçınılmaz olmuştur. Killerin kolay biçim verilmesi ve çevrede kolay bulunması yaygın kullanımını artıırmıştır. Tarihsel süreçte seramiklerin sadece günlük gereksinim kapları olarak kalmadığı; aydınlatmayı sağlayan kandiller, bina inşaatlarında kullanılan tuğla ve kiremitler, takı ve süs eşyaları, ölü küllerinin saklandığı kaplar ve lahitlerin yanı sıra, çocuk oyuncaklarına kadar geniş bir ürün yelpazesine sahip olduğunu göstermektedir (Erman, 2012: 20).

Arkeolojik kazı ve araştırmalarda bulunan pişmiş toprak kaplarının yapısı, biçimlendirme teknikleri, kap biçimleriveyüzey görünümleriincelendiğinde, kullanıldıkları çağın gereksinimleri, ulaştıkları teknoloji düzeyi, beğenileri, farklı toplumların birbirleriyle olan ilişkileri, sosyal ve etnik farklılıkları ve yaşam süreçleri ile anlaşılabilmektedir (Ökse, 1993: vIII).

Seramik üretiminde şekillendirme elle, çarkta ve kalıpta olmak üzere üç farklı yöntem uygulanarak yapılmaktadır. Sekillendirme aşaması seramik üretiminin en önemli aşamalarından biridir. Antik dönemlerde yuvarlak formların çoğunlukla elle ve çarkta şekillendirildiği bilinmektedir. Çanak çömleklerin elle şekillendirilmesine ilk olarak Neolitik dönemde (M.Ö. 8000-5500) başlanmıştır. Bu ilk örneklere Ürdün, Irak ve İran'da rastlanmışır. Diğer örnekler Sümer'de M.Ö. 3250 yıllarında, Mısır'da M.Ö. 2750 yıllarında görülür. Yunanistan'da ise elde üretim, Erken Bronz Çağı (M.Ö. 3000-2500) süresince uygulanmıştır. Aynı dönemlerde Kıbrıs ve Girit'te de el yapımı örnekler görülmektedir (Zengin, 2007:19). Çarkta şekillendirmenin tarihsel sürecine bakıldığında ise; çömlekçi çarkının ne zaman ve kimler tarafından icat edildiği bilinmemektedir. Fakat bilinen en eski çömlekçi çarkı Mezopotamya'daki Uruk yerleşiminde bulunmuştur ve M.Ö. 3500'lere tarihlenmiştir. M.Ö. 3000'li yıllarda çömlekçi çarkının Kuzey Mezopotamya'dan tüm Mezopotamya'ya, batı Hindistan'a, Suriye'ye, Mısır'a ve Ön Asya'ya yayılmış olduğu, arkeolojik kazılarla ortaya çıkarılmışır. Anadolu'da ise çarklı çömlekçilik, ilk kez M.Ö. 3000-2000 yılları arasında Kayseri dolaylarında, Alişar'da, Boğazköy'de ve Troya'da görülmektedir. Antik dönemde çarklar, elle ve ayakla çevrilen olmak üzere iki çeşittir. Bunlar ağır tahtadan, pişmiş topraktan veya taştan yapıımış, yaklaşık $60 \mathrm{~cm}$ çapındaki bir disk şeklindedir. Ayakla çevrilen çömlekçi çarkı, ilk kez Yukarı Mısır'da Osiris kutsal alanının duvar kabartmalarında betimlenmiştir (Zengin, 2007: 20).
Pişirim, kil (seramik) bünyeyi kalııı hale getirir. Seramik pişirim teknikleri incelendiğinde; açık pişirim olarakisimlendirilen en ilkel pişirimyönteminden odunlu pişirim uygulamalarının yapıldı ̆̆ geniş kapasiteli fırınlara kadar pek çok örneği görebilmek mümkündür. Günümüzde Anadolu'da açık pişirim hala kullanılmakta olup, vazgeçilmeyen bir uygulama olarak varlığını sürdürmektedir.

Bin yıllar boyunca, antik dünyanın büyük bölümünde yaygın olarak üretilen seramikler günümüzde son teknolojiye ayak uydursa bile, hala bazı konularda eski çağlara ait görüş, anlayış ve yöntemler geçerliliğini korumaktadır ve geleceğe ışık tutacak niteliktedir. Bu bağlamda; Anadolu kültür tarihi, özellikle arkeoloji dünyası için önemli bir yer olan Lykia, 19. yy'dan günümüze birçok araştırmacı ve bilim insanlarının araştırma yaptığı bir bölge olmuştur. Güneybatı Anadolu'nun bu özgün coğrafyası ve kurulan yerleşim alanlarının çeşitliliği dikkate alındığında; arkeolojik olarak yaşama dair eserleri tüm ihtişamıyla sunmaktadırlar. Likya Bölgesi'nin önemli kentlerinden birisi olan Rhodiapolis, Likya'nın doğu sınırındaki son Likya kentidir. Bu kentte 2006 yılından beri yapılan bilimsel arkeolojik kazılar gerek Likya Bölgesi tarihi açısından gerekse de Klasik Dönem'den Bizans Dönemi'ne kadar Anadolu seramik kronolojisi açısından önemli bilgiler sunmaktadır (Görsel 1).

Rhodiapolis'te ele geçen seramik ürünler kazı dönemlerinde Doç. Dr. İsa Kızgut başkanlığında dönem ve çeşitlilik olarak incelenmiş ve gruplandırılmıștır. Roma dönemi seramik pişirme kapları ile Roma Dönemi tabakları, çanakları ve kâseleri üzerine bilimsel çalışmalar yapılmış̧ır (Fırıncı, 2010; Akın, 2012). Daha önce yapılan inceleme ve akademik çalışmalarda üretim atıklarının çeşitliliği göze çarpmıştır. Söz konusu buluntuların bol miktarda olması Rhodiapolis antik kentinin önemli bir seramik üretim merkezi olabileceği kanaatini güçlendirmektedir.

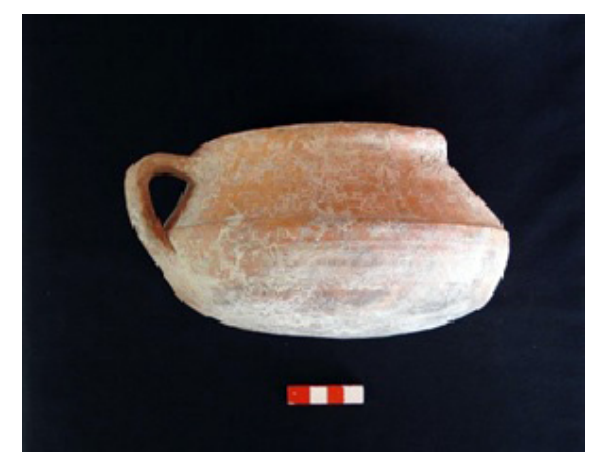

Görsel I. Rhodiapolis seramiklerine ait bir örnek (M.Ö.4 yy) 
Bu çalışmada, Rhodiapolis yerel seramik üretim atıkları ışı̆̆ında; seramik üretiminde izlenen şekillendirme ve pişirme yöntemlerine dair uygulama aşamaları incelenmiş ve günümüz üretim yöntemleriyle arasındaki benzerlik ve/veya farklılıklar açıklanmıştır.

\section{Rhodiapolis Seramik Atıkları}

Rhodiapolis antik kenti kazılarında bulunan seramik üretim atıkları büyük çeşitlilik sunmaktadır. Bu atıklar seramik üretim teknikleri hakkında önemli ipuçları sergilemektedir (Görsel 2). Bölgede seramik üretiminin yapıldığını gösteren farklı formlarda ürünler de ele geçmiştir. Bilindiği gibi seramik üretimi şekillendirme ve pişirim olmak üzere iki ana bölüme ayrılmaktadır. Bu çalışmada, Rhodiapolis kazılarından ele geçen seramik üretim atıkları şekillendirme ve pişirim başlıklarında incelenmiş, formu anlaşılabilen parçalar seçilmiştir. Bu örnekler ışığında, hammadde çeşitliliği, şekillendirme, dip alma işlemi, pişirim, fırın onarımı gibi başlıklarda değerlendirmeler yapılmıştır.

\section{Seramik Şekillendirme iş̧lemi}

Seramik üretiminde şekillendirme; elle, çarkta ve kalıpta olmak üzere üç farklı yöntem uygulanarak yapılmaktadır. Şekillendirme aşaması seramik üretiminin en önemli aşamalarından biridir. Bu aşamada hazırlanacak seramik forma nihai şeklini vermek el becerisi ve deneyim gerektirir

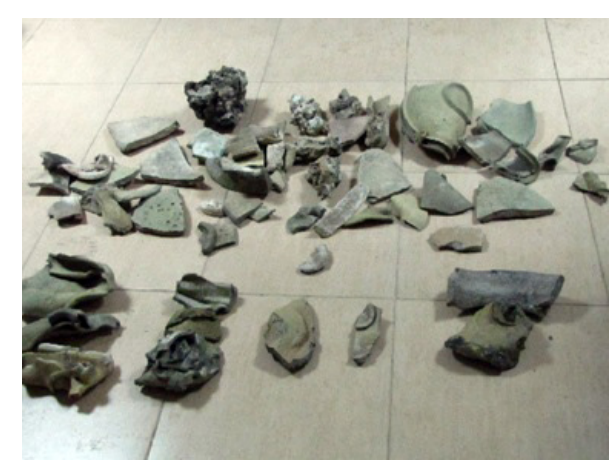

Görsel 2. Rhodiapolis seramik üretim atıkları

Rhodiapolis seramik atıkları incelendiğinde; kazılarında bulunan amorf malzeme, iki ayrı seramik çamurundan oluştuğu kanısını uyandırmaktadır (Görsel 3). Bu özellikler, Rhodiapolis çömlekçilerinin ürünlerini bir tek kil yatağından almadıkları ve üretime göre farklı killerden yararlandıkları düşüncesini önemli ölçüde desteklemektedir. Bunun yanında, ayrı killerden üretilen seramiklerin aynı fırında eşit sıcaklıkta ve bir arada fırınlanmış olabileceğini de düşündürmektedir.

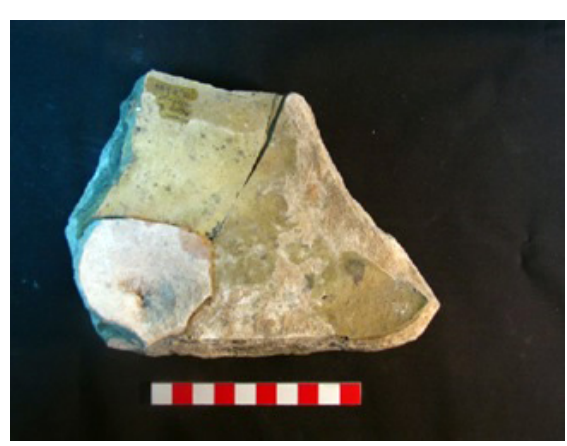

Görsel 3. Farklı çamur kullanımına ait seramik buluntu

Seramik çalışmalarındaki üretimin aşamaları göz önüne alındığında, tabağın çarkta şekillendirilip kurumaya yakın bir aşamaya kadar bekletildiği, yani deri kıvamında iken ters çevrilerek ayak kısmının tıraşlandığı bilinmektedir. Seramik üretiminde genellikle metal bir kesici alet ile yapılan tıraşlama sonrası ürünlerden artan çamurlar, sert olduğu için ayrı bir kaba konulmakta ve bu kap içerisinde yumuşatılarak karıştırımaktadır (Peter, 1997: 91). Rhodiapolis kazılarındaki bir diğer amorf malzeme örneği Görsel 4'de yer alan seramik buluntudur. Bu buluntunun; seramik şekillendirme işlemi tamamlandıktan sonra, kaide bölümünün traşlama sırasında artan çamurların bir kap içerisine bırakıldığı ve kabın formunu almış bir malzeme olduğu düşünülmektedir (Görsel 4).

$\mathrm{Bu}$ artıkların neden pişirildiği kesin olarak anlaşılamasa da, fırınlama aşamasında günümüz seramikçilerinin de kullanmakta olduğu fırın desteği ya da gözetleme deliği gibi fırın bölümlerinin seyyar kapağında kullanılmış olabileceği de güçlü bir olasilık olarak görülmektedir (Fraser, 2010: 145146; Hasaki, 2002: 478; Kura, 1989: 144).

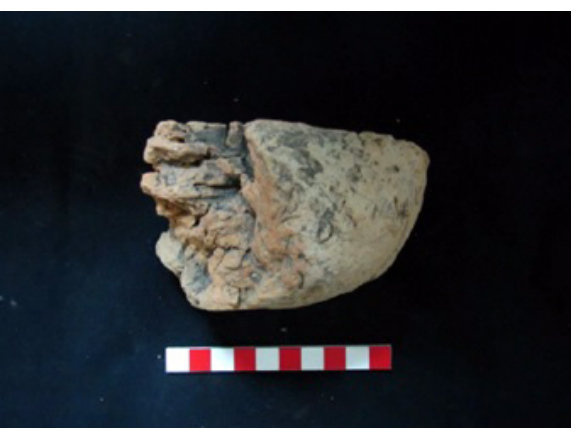

Görsel 4. Traşlamadan çıkan artıklara ait seramik buluntu 
Şekillendirme aşamasında değerlendirilen bir diğer seramik buluntu örneği keçiye aitolduğu düşünülen ayakizinin bulunduğuseramikparçasıdır (Görsel 5). Söz konusu buluntu, kiremit ve tuğla gibi seramiklerin üretildiği alanlar ve işlikler hakkında bilgi verir. Bu işliklerin hayvan yetiştiricilerinin bulunduğu yere yakın ya da iç içe olabilecekleri düşüncesini güçlendirmektedir.

Ayrıca, kiremit ve tuğla üretiminde su yataklarına yakınlık ve kurutma işlemi için geniş alanlar gerektiğinden açık alanda üretim yapılması olasıdır. Sonuç olarak; Rhodiapolis çömlekçilerinin büyük olasılıkla şehir dışında kil ve su yataklarına yakın bir bölgede, açık ve düz alanda, hayvanların da bulunabileceği bölgede üretim yaptıkları görüşünü kuvvetlenmektedir.

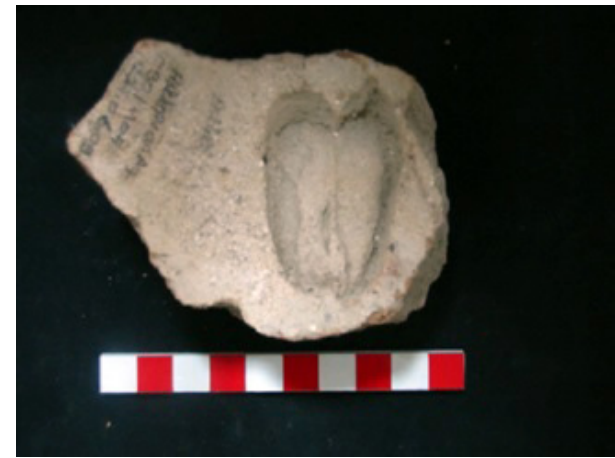

Görsel 5. Dış mekâna dair seramik buluntu

\section{Pişirme Aşamalarını Gösteren Üretim Atıkları}

Rhodiapolis kazılarında fırınlama işleminde deforme olduğu düşünülen iç içe geçmiş çanak buluntusu ele geçmiştir. Bu buluntu incelendiğinde, çarkta şekillendirildiğinde deforme olduğu ya da bozulduğu tahmin edilen tabak kalıntıları olması muhtemel bir yapı sergilemektedir (Görsel 6). Ancak buluntunun görünümü çamur çok yumuşak kıvamda iken yamultularak bir kenara bırakılan bu seramik parçasının neden pişirilmiş olduğu sorusunu akla getirmektedir.

Seramik çalışmalarındaki üretimin aşamaları göz önüne alındığında, tabağın çarkta şekillendirilip kurumaya yakın bir aşamaya kadar bekletildiği, yani deri kıvamında iken ters çevrilerek ayak kısmının tıraşlandığı ve tamamen kurutulduktan sonra firınlandığı bilinmektedir (Cosentino, 1997: 91; Birks, 1993: 60). Seramik üreticilerinin de bildiği üzere, deri kıvamına gelmiş ve tıraşlama yapılacak kadar kurumuş bir ürün bu kadar eğilmemektedir. Bu tür eğilme durumuna ancak fırında çok yüksek sıcaklıklarda pişirilmiş ürünlerde karşılaşılmaktadır (Fraser, 2010: 48). Ayrıca bu amorf

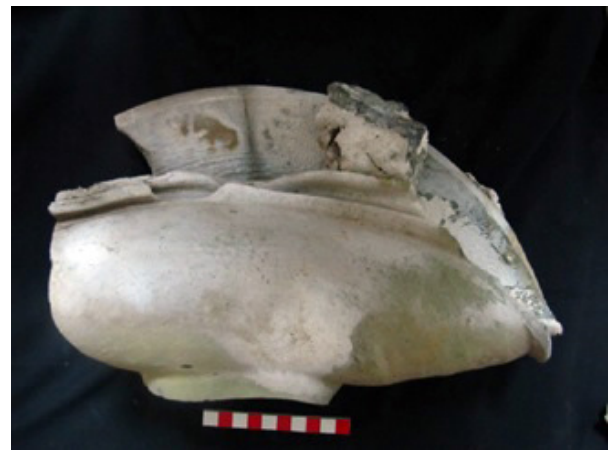

Görsel 6. Lç içe geçmiş seramik çanak buluntu örneği

malzeme Rhodiapolis seramik üretiminde tabakların fırınlama işleminin üst üste konularak yapıldığını gösterir ve seramik üretimine ışık tutması açısından son derece önemlidir. Aynı zamanda iç içe geçmiş şekilde yapı sergileyen bu tabakların fııınlama işleminde bu yapıyı almış olması, antik dönemlerde seramik atölyesinin ve seramik fırınının bulunması intimalini de arttırmaktadır. Simdiye kadarki süreçte Rhodiapolis kazılarında seramik fırın buluntusuna rastlanmamış olsa da, bu buluntuların varlığı seramik fırınının olabileceğini destekler niteliktedir.

Rhodiapolis'de 2006 yılı kazılarında bulunan diğer amorf malzemenin süzgeçli kap buluntusu olabileceği düşünülmüştür (Görsel 7). Seramik fırınlarında yüksek sıcaklığa ulaşan pişirimler sırasında malzeme üzerinde deformasyonlar meydana gelmektedir. Bu deformasyonlar ateşin IsISI ve süresine bağlı olarak formda büyük değişikliklere neden olabilmektedir. Bulunan seramik parçasında meydana gelen bu eğilme hareketi, Rhodiapolis fırınlarının çok yüksek sıcaklıklara çıktığı ve bu derecede uzun süre kalabilecek kapasitede fırınlar olabileceği hakkında ipuçları vermektedir.

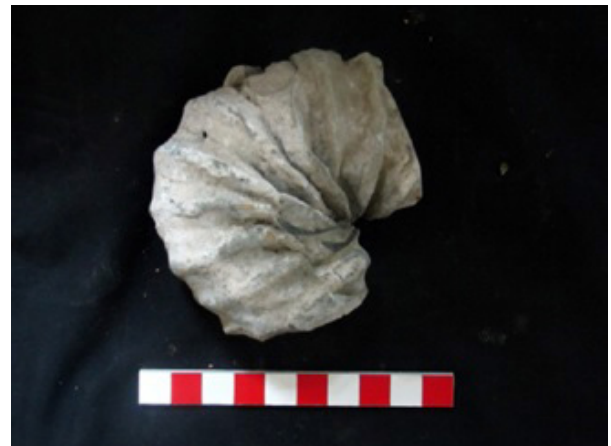

Görsel 7. Süzgeçli kap boyun kısmına ait seramik buluntu 
Rhodiapolis kazılarında fırınlama sistemi ile ilgili olduğu düşünülen seramik Görsel 8'deki amorf malzemedir. Bu kap parçasında da pişirim sıcaklı̆̆ı ve tekniğine bağlı olarak yüzeyde kırılma ve çatlakların oluştuğu düşünülmektedir. Seramik pişirimi sırasında, daha yoğun ateş alan bölgenin, günümüz yerel çömlekçilerinin deyimiyle "ateş vurması" denilen hatayı oluşturduğu bilinmektedir (Taşhomcu, 2014). Isı kaynağının hemen yakınına yerleştirilen seramik ürün, ateş koridorunun önünde kaldığı zaman ısının uzun süre aynı yönde akması ile seramik malzemenin aşırı erimesine neden olmaktadır. Benzer şekilde, Akdeniz Bölgesi Antalya ili Serik ilçesi yakınlarından alınan kil örneği ile yapılan çalışmada, gazlı fııın ortamında "beg" diye isimlendirilen fırın ısı kaynağının karşııına gelen üründe meydana gelen deformasyon ve şekil bozukluğu gözlenmektedir (Görsel 9). Illginç olan bir başka konu ise, yine Akdeniz bölgesi kili ile yapılan bu seramiğin Rhodiapolis killerinin pişiriminde olduğu gibi yeşil renkte olmasıdır.

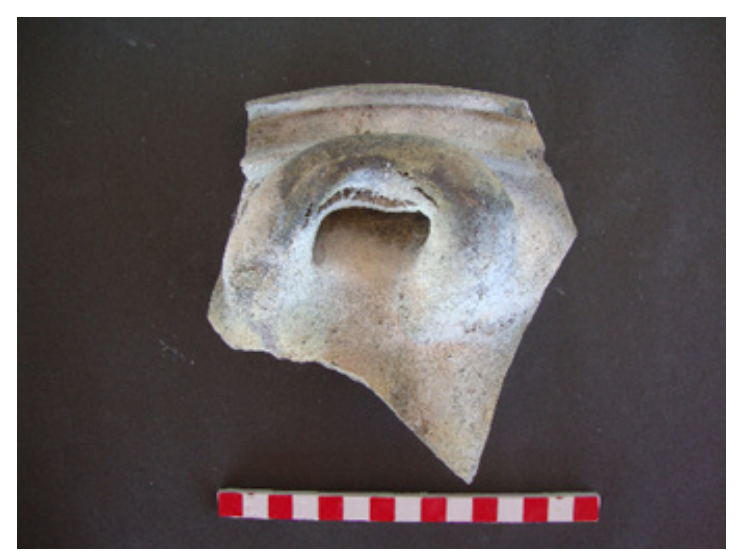

Görsel 8. Fırınlama işleminde ateş vurmasına maruz kalmış seramik buluntu

Fırınlama işlemlerinde karşılaşılan teknik sorunlardan bir tanesi de kabarcık oluşumudur. Kabarcık oluşumu bazen kaynama olarak adlandıılır. Kabarcık oluşan alan, sayısız kraterler, baloncuklar ve iğne ile yapılmış gibi delikleri içerir. Bu hatanın genel nedeni, aşırı pişirmedir. Isıtma elemanlarına çok yakın yerleştirilen seramik ürünler aşırı oranda pişebilir. Ayrıca, seramik bünye olgunlassma noktasına yaklaștığında cok hızlı pişirme de bu problemi ortaya çıkarabilir (Fraser, 2010: 87). Rhodiapolis antik kentinde kazılarda bulunan seramik parçası üzerinde oluşan kabarcıkların yüksek sıcaklıklardan kaynaklandığı sanılmaktadır. Bu buluntunun fırında oluşan yüksek sıcaklık etkisiyle ya da dengesiz alev akışından dolayı bu formda oluştuğu düşünülmektedir (Görsel 10)

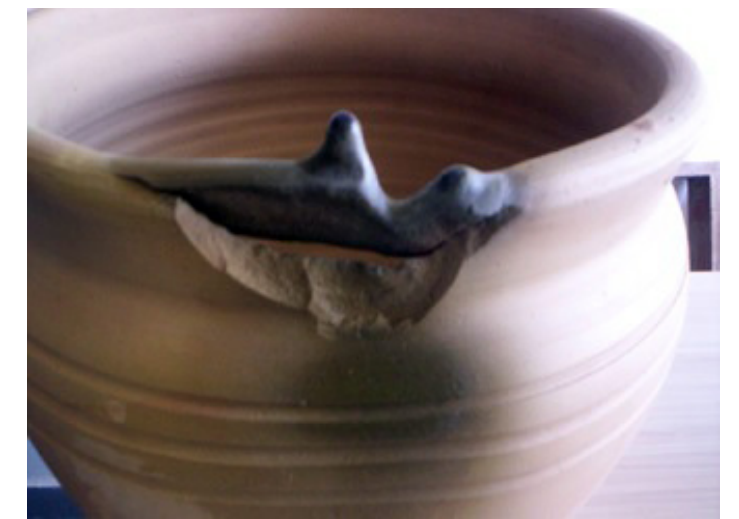

Görsel 9. Fırınlama işleminde ateş vurması örneği ( Günümüz uygulaması)

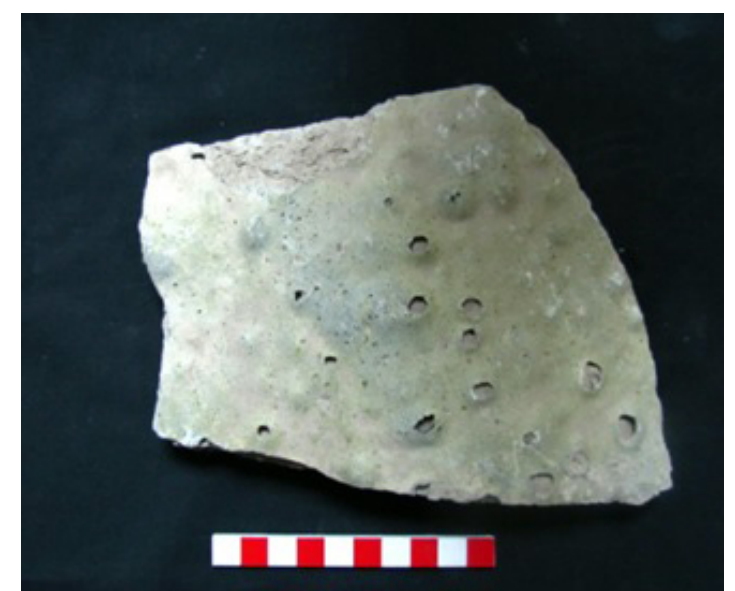

Görsel I0. Kabarcıklı seramik buluntu örneği

Seramiklerin pişirilmesi işleminde fırın yapıları da oldukça önemlidir. Rhodiapolis 2006 yılı kazılarında bulunan bir seramik örneğinin şekilsiz bir formda olması ilk bakıșta neden pişirildiği konusunda soru işaretleri oluşturmuştur (Görsel 11). Bu seramik buluntunun açıklanması için Karacasu'da çömlekçilik yapan Ali Bardak ile görüşülmüş ve bir değerlendirilme yapılmıştır (Bardak, 2013). Ayrıca, literatürde ilkel fırınlarda ürün pişirimleri sırasında fırında sıvalarda dökülmeler olabildiği belirtilmiştir (Sevim, 1991: 41). Bu nedenle, Rhodiapolis buluntusu amorf malzemenin fırın iç sıvası olabileceği görüşü ağırlık kazanmıştır. Bu amorf örneğine ait benzer renkteki seramiklere Karacasu atölyesi çöplerinde de rastlanmıştır (Görsel 12). Bu buluntular ile Rhodiapolis çömlekçilerinin 
kullandığı fırınların çok yüksek sıcaklık kapasitesine sahip olduğu ve uzun süreli yanma sağlandığı anlaşılmaktadır.

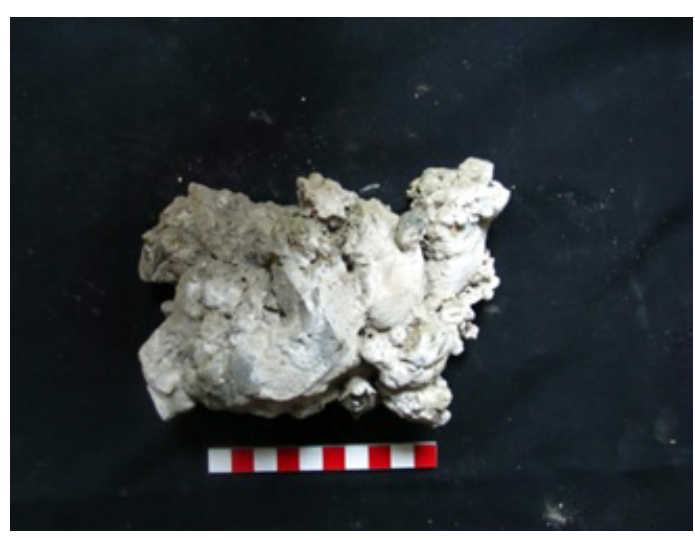

Görsel II. Fırın sıvası buluntu örneği

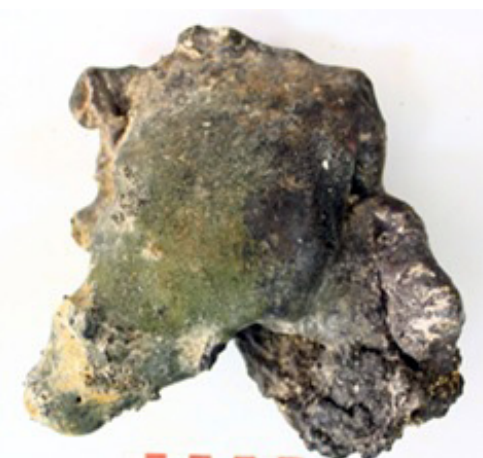

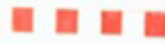

Görsel I2. Karacasu firın sıvası örneği (Günümüz uygulaması)

\section{Sonuç ve Öneriler}

Likya Bölgesi içinde Rhodiapolis antik kentinde bulunan üretim atıklarının çeşitliliği, yerel seramik üretim merkezinin olabileceği düşüncesini destekler niteliktedir. Özellikle seramik pişirme kapları ve Roma dönemi tabak, çanak ve kâse formlarının çeşitliliğinin yanı sıra buluntulardaki atıkların zenginliği, antik dönemdeki seramik üretiminde şekillendirme ve pişirme tekniklerinin açıklanabilmesi açısından oldukça önem taşımaktadır. Bu çalışmada; Rhodiapolis 2006 - 2012 yılları arasında yapılan kazı çalışmalarında ortaya çıkartılan yoğun miktardaki üretim atığı malzemeleri incelenmiş ve günümüz seramik şekillendirme ve pişirim teknikleri ile ilgili benzerlik ve farklılıklar değerlendirilmiştir.

Seramik üretimde kullanılan kilin yapısı, şekillendirme ve pişirme yöntemleri onu üreten toplumun ulaştığı bilgi ve teknoloji seviyesinin göstergesi niteliğindedir. Rhodiapolis kazılarında bulunan seramik üretim atığı malzemeler ile günümüzde Akdeniz Bölgesi'nde bulunan çömlekçilik merkezlerindeki malzemelerin karşılaştııı ması seramik geleneğinin coğrafi yayılımını da gösterecektir. Seramiklerin üretiminde benzerliklerin seramik geleneğinin nakledildiğinin en güzel örneğidir. Bu yüzden, seramik üretimindeki yöntemlerin antik dönemdeki buluntularla kıyaslanması geleneğin uygulanma süreci ve tarihlendirilmesi açısından çok önemlidir. Bu çalışmaya ek olarak; farkı ıntik kentlerde bulunan seramik buluntuların gerek arkeologlar gerekse seramik sanatçılarının işbirliği ile tespit edilmesi ve incelemelerinin yapılması gerçekleştirilmelidir. 


\section{Kaynakça}

Akın, F. (20I2). Rhodiapolis Seramikleri Roma Dönemi Tabakları, Çanakları ve Kaseleri "2006-20 I I Buluntuları", Yüksek Lisans Tezi, Akdeniz Üniversitesi Sosyal Bilimleri Enstitüsü, Antalya.

Bardak, A. (20/3,20 Nisan). Seramik Fırınları Ve Çömlekçilik Üzerine Söyleşi. Karacasu, Aydın.

Birks, T. (1993). The Complete Potter's Companion. London: Conran Octopus Limited.

Cosentino, P. (1997). The Encyclopedia of Pottery Techniques. Running Press Book

Publishers.

Erman, D.O. (20I2). “Türk Seramik Sanatının Gelişimi: Toprağın Ateşle Dansı”. ACTA TURCICA, 4(I): I8-33.

Fırıncı, S. (2010). Rhodiapolis Seramikleri Roma Dönemi Pișirme Kapları "2006-2009 Buluntuları, Yüksek Lisans Tezi, Akdeniz Üniversitesi Sosyal Bilimler Enstitüsü, Antalya.

Fraser, H. (20I0). Seramik Hataları ve Çözüm Yöntemleri (çev. Z. Mete ve i.Özkan), Karakalem Kitabevi Yayınları.

Hasaki, E. (2002). Ceramic Kilns in Ancient Greece: Technology and Organization of Ceramic Workshops, Doktora Tezi, University Of Cincinnati, Ohio.

Kura H. (1989). Endüstriyel Seramik Tasarımında Biçim ve Üretim Yöntemleri, Doktora Tezi, Mimar Sinan Güzel Sanatlar Üniversitesi Sosyal Bilimler Enstitüsü, İstanbul.

Ökse, A. T. (1993). Önasya Arkeolojisi Seramik Terimleri. İzmir: Arkeoloji ve Sanat Yayınları.

Peter, C. (1997). The Encyclopedia of Pottery Techniques. London: Headline Book Publishing.

Sevim, C. (199I). Illkel Fırınlar, Yüksek Lisans Tezi, Anadolu Üniversitesi Sosyal Bilimler Enstitüsü, Eskişehir.

Taşhomcu, A. (20/4, I5 Mart). Pişirim Üzerine Söyleşi. Onur Seramik, Serik, Antalya.

Zengin, F. E. (2007). Antik Yunan Seramiklerinde Çömlekçilik Konulu Sahneler, Yüksek Lisans Tezi, Dokuz Eylül Üniversitesi Sosyal Bilimler Enstitüsü, İzmir.

\section{Görsel Kaynakları}

Görsel I: Yazar tarafindan çekilen fotoğraf, 2010

Görsel 2: Yazar tarafindan çekilen fotoğraf, 2010

Görsel 3: Yazar tarafindan çekilen fotoğraf, 2010

Görsel 4: Yazar tarafindan çekilen fotoğraf, 2010

Görsel 5: Yazar tarafindan çekilen fotoğraf, 2010

Görsel 6: Yazar tarafindan çekilen fotoğraf, 2010

Görsel 7: Yazar tarafindan çekilen fotoğraf, 2010

Görsel 8: Yazar tarafindan çekilen fotoğraf, 2010

Görsel 9: Yazar tarafindan çekilen fotoğraf, 2010

Görsel 10: Yazar tarafindan çekilen fotoğraf, 2010

Görsel I I: Yazar tarafindan çekilen fotoğraf, 2010

Görsel I2: Yazar tarafindan çekilen fotoğraf, 2010 